\title{
Oral Health Status of Psychiatric Patients Among the Residents of Lahore
}

${ }^{1}$ Saeed ur Rehman, ${ }^{2}$ Nauman Rauf Khan, ${ }^{3}$ Amna Nauman Khan, ${ }^{3}$ Moeed Ramzan, ${ }^{4}$ Eezzah Laraibe, ${ }^{4}$ Hooria Haq, ${ }^{4}$ Anum Abbass

${ }^{1}$ Department of Psychiatry, Sharif Medical \& Dental College, Lahore.

${ }^{2}$ Department of Oral Pathology, Sharif College of Dentistry, Sharif Medical \& Dental College, Lahore.

${ }^{3}$ Department of Community Dentistry. Sharif College of Dentistry, Sharif Medical \& Dental College, Lahore.

${ }^{4}$ House Officer, Sharif Medical \& Dental College, Lahore.

\begin{abstract}
Introduction: Psychiatric illness is known to be amongst the most rapidly growing diseases of the world and it is also a risk factor for poor dental health. In psychiatric patient, poor oral health is an alarming factor and occurs as a result of reduced dental care activities, lack of awareness regarding presence of poor oral health, difficulty in understanding or memorizing proper oral hygiene practices and large spans of sleep due to the side effects of psychiatric medications. Aims \& Objectives: To determine the oral health status of the psychiatric patients of Lahore. Place and duration of study: This study was conducted in Psychiatric OPD, Sharif Medical City Hospital for the period of six months. Material \& Methods: A cross sectional study was done to assess oral/dental health of 60 psychiatric outpatients presenting at Sharif Medical City Hospital. A self-devised proforma was used to enter all characteristics including different types of psychiatric disorder, oral hygiene practices and intra oral findings. Results: Major depression (non-resistant) was seen to be the most common psychotic disorder in this study and schizophrenia to be the least common. Frequency of the caries was seen to be $61.6 \%$ among the psychiatric patients. The Mean Decayed Missing, Filled Teeth (DMFT) was calculated to be 3.83+ 0.469 (S.D+3.632). Mean Community Periodontal Index of Treatment Need (CPITN) score was $1.37+0.130$ (S.D+1.008). Bleeding on probing was seen in $40 \%$ of the patients, whereas, calculus formation and pocket formation were seen in $40 \%$ and $11.7 \%$ patients respectively. Maximum bleeding and calculus formation was seen among the major depression (non-resistant) group patients. DMFT was strongly associated with the psychiatric patients with linear by linear association of 0.84 . CPITN was significantly associated with education and soft tissue conditions with Pearson Chi-Square values of $\mathrm{p}<0.028$ and $\mathrm{p}<0.001$ respectively. Frequency of caries and DMFT score were both seen to be significantly increased in psychiatric patients. Efforts to emphasize dental health awareness and improve oral hygiene practices in psychiatric patients are needed. Conclusion: Frequency of caries, DMFT and CPITN scores are significantly greater in psychiatric patients with Major Depression (Resistant),substance abuse and post-traumatic stress disorder (PTSD).
\end{abstract}

Key words: Oral health, Psychiatric disorder, Mental health literacy, Schizophrenia, Bipolar disorder, Alzheimer's disease.

\section{INTRODUCTION}

$\mathrm{O}$ ral health is of fundamental importance to our physical well-being. Poor dental health is associated with systemic diseases such as stroke, coronary heart disease and respiratory disease. ${ }^{1}$ Poor oral health also affects our psychological and social functioning. ${ }^{2}$

Patients of psychiatric illness have higher rates of oral disease and poorer dental health than mentally healthy individuals. ${ }^{3,4}$ This is largely due to changes in behavior, neglect of social contacts, loss of care for proper hygiene and appearance. ${ }^{5}$ Other than these factors one of the most important factors leading to poor oral hygiene is the recognition of psychiatric disorder itself known as mental health literacy level(MHL). ${ }^{6}$ Mental health literacy (MHL) level is also known as knowledge or belief of getting a mental disorder. This level indicates that the individual is aware of psychotic illness he or she is suffering from. ${ }^{7}$ Delay in the recognition of MHL leads to poor overall management and prevention. ${ }^{8}$ Psychiatric medication may also contribute to oral ill health. ${ }^{9,10}$ It has also been found that psychiatric patients in general had worse DMFT score, worse oral hygiene and increased frequency and severity 
of periodontitis. ${ }^{9}$ However, there are different types of psychiatric illnesses and literature on oral health assessment in relation to each type is scarce. Different types of psychiatric illnesses include schizophrenia (schizo-affective), major depression (resistant type), major depression (non-resistant type), bipolar disorder (B.A.D), Alzheimer's disease, Attention-deficit/ hyperactivity disorder (ADHD), post-traumatic stress disorder (PTSD), anxiety disorder, obsessive compulsive disorder (OCD), acute psychosis, conversion disorder, feeding and eating disorder, Attention-deficit/ hyperactivity disorder (ADHD), substance abuse and others. ${ }^{11}$

Literature reports several studies showing strong correlation between psychiatric diseases and poor oral health. Studies conducted in India ${ }^{12}$ reports worse dental health, with prevalence of caries among psychiatric patients to be $54.89 \%$, also poor hygiene practices among the non-institutionalized psychiatric patients. ${ }^{13}$

Dental health among psychiatric outpatients is seen to be worse among different types of psychiatric diseases especially among male patients with schizophrenia. ${ }^{14}$ These psychiatric outpatients are reported not visiting dentist regularly, not brushing their teeth regularly, having higher DMFT scores and half of their tooth decay gone untreated compared to national average of one quarter. ${ }^{15}$ These patients also have TMJ problems as well as increased DMFT, plaque and bleeding indices. Scalloped tongue is another salient feature of such patients. ${ }^{13,16}$ In severe types of psychiatric disorders such as bipolar disorder (B.A.D), Alzheimer's disease and schizophrenia patients have three times more chances of losing all their teeth in comparison to healthy individuals. ${ }^{17}$ In case of resistant depression, post-traumatic stress disorder (PTSD) along with schizophrenia and BAD there are higher rates of teeth with untreated caries. ${ }^{18}$ This deficit in dental health and increase in oral diseases of psychiatric patients translates into significant effects on quality of their life. ${ }^{19}$

There is a scarcity of literature regarding oral health status and oral hygiene practices in relation to psychiatric patients in Pakistan. There are many universal oral health indices that are being used among the patients, however, decayed missing, filled teeth (DMFT) and the community periodontal index of treatment need (CPITN) are the most commonly used indices in research for overall oral health assessment. ${ }^{20}$

In this study we aimed to study the dental health status of psychiatric patients visiting the outpatient department of Sharif Medical Complex (SMC). This study will contribute towards increasing awareness among dentists regarding consulting psychiatric patients with great care and informing them about the benefits of having good oral hygiene and practices.

The objective of this study was to assess oral health status, determination of oral hygiene practices of outpatients in psychiatric clinic in SMC and relate it with their demography and psychiatric disorder.

\section{MATERIAL AND METHODS}

A cross-sectional descriptive study was conducted at Psychiatry and Dental O.P.D. of Sharif Medical City Hospital, Lahore lasting six months from October 2017 till March 2018. 60 Patients of psychiatric illness presenting to psychiatry OPD fulfilling the criteria for ICD-10 classification of mental and behavioral disorder ${ }^{21}$ were included in the study irrespective of gender. However, pediatric age group patients i.e., 18 years and below were excluded from the study. Psychiatric patients that were aggressive or uncooperative were also excluded from the study. Sample size was calculated using the formula of comparison of the two means, keeping power of study $90 \%$ and desired level of significance is 0.05 and it was calculated to be 113 , however, an initial pilot of 60 subjects were received during the time of six months as mentioned above. Convenient sampling technique was used. The nature of the study was explained to the patients and caregivers; written informed consent was taken after assuring them of complete confidentiality.

All patients were assessed according to the following pattern, based upon a self-devised proforma. Age of patient, gender, marital status, education and socio-economic level were elicited among socio-demographic factors. Among clinical factors, the following oral cavity findings such as frequency of tooth brushing per day, presence of Temporomandibular joint (TMJ) clicking, limited mouth opening, nail, lip or tongue biting, community periodontal index of treatment need (CPITN), decayed-missing-filled teeth (DMFT) scores (0-28), soft tissue findings, xerostomia, masticatory muscle tenderness, bruxism, scalloped tongue, carious teeth, filled teeth, tooth staining \& bleeding index were all noted on the proforma and then entered in IBM SPSS version 20.

\section{Statistical analysis:}

Psychiatric variables were, duration of illness, presence of tremor, current psychiatric medicine, presence of smoking and psychiatric diagnosis. Schizo-affective is a sub-type of schizophrenia ${ }^{22}$; therefore both groups are combined under the 
heading of schizophrenia. The qualitative data is presented as frequency and percentages; quantitative data is presented as mean and standard deviation, statistical significance is assessed using Chi Square test \&t-test with $\mathrm{p}$ value less than or equal to 0.05 is considered statically significant.

\section{RESULTS}

Study was done on total of 60 patients, ranging from 19-78 years, with maximum number of patients $63.3 \%$ belonged to the age group of $21-40$ years. Mean age of these patients was 31 years $(\mathrm{SD} \pm 12.9)$ and $(\mathrm{SEM} \pm 1.67)$. Majority of the patients were married with $68 \%$ belonging to either middle class or lower class. Predominant number of patients could easily read and write and with only $10 \%$ illiterate group, as shown in Table-1.

Frequencies of different psychiatric diseases among the study group are given in Chart 1. It was seen that major depression (non-resistant) is the most affecting disease (38\%) followed by anxiety disorder (17\%). Schizophrenia, Posttraumatic stress disorder (PTSD) and attention deficit/ hyperactivity disorder (ADHD) were the least common reported diseases i.e., only $2 \%$ each. Oral health practices are not good with majority of the patients brushing only once or not brushing at all in about $81 \%$ of the patients.

Normal Periodontium is seen in $26.7 \%$ of the cases. Frequency of the caries is seen to be $61.6 \%$ among the psychiatric patients. Bleeding on probing was seen in $40 \%$, calculus $40 \%$ and pocket formation in $11.7 \%$. The mean DMFT and CPITN scores along with their standard error, standard deviation and ranges are given in Table-2.

Differences in DMFT and CPITN scores with age are not statistically significant. Bleeding of gums, teeth staining, scalloped tongue and smoking all are seen to be not statically significantly related with age. Maximum bleeding gums and calculus formation is also seen in major depression (nonresistant) group as shown in Chart-2. Oral hygiene measures such as caries formation, bleeding gums, pocket formation, calculus formation, DMFT scores and CPITN scores were higher in Major Depression (Resistant), substance abuse and PTSD disease group patients. Some of CPITN measures among all the psychiatric disorder groups are shown in Chart-2 with Major Depression (Non-resistant) having the maximum number of patients. Psychiatric groups with minimum DMFT and CPITN scores were seen to be amongst schizophrenia, obsessive compulsive disorder (OCD) and bipolar disorder (BAD).
Periodontal health index CPITN was not seen to be significantly associated with education with signifying poor oral hygiene to be more among the illiterate and under Matric education patients with $\mathrm{p}$ $=0.028$ as shown in Table-3. No significant relation was established between CPITN and psychiatric disorder patients with $\mathrm{p}=0.176$ as shown in Table-4. Caries prevalence index DMFT score is seen to be strongly associated with the psychiatric patients linear by linear association of 0.84 proving high prevalence of caries among the psychiatric patients.

\begin{tabular}{|c|c|c|}
\hline Characteristics & Frequency & Percentage $\%$ \\
\hline \multicolumn{3}{|c|}{ Age in years } \\
\hline$<20$ & 12 & 20.0 \\
\hline $21-40$ & 38 & 63.3 \\
\hline $41-60$ & 8 & 13.3 \\
\hline 61 and above & 2 & 3.3 \\
\hline \multicolumn{3}{|c|}{ Gender } \\
\hline Male & 25 & 41.7 \\
\hline Female & 35 & 58.3 \\
\hline \multicolumn{3}{|c|}{ Marital Status } \\
\hline Married & 35 & 58.3 \\
\hline Unmarried & 22 & 36.7 \\
\hline Divorced & 2 & 3.3 \\
\hline Widow & 1 & 1.7 \\
\hline Married & 35 & 58.3 \\
\hline Unmarried & 22 & 36.7 \\
\hline \multicolumn{3}{|c|}{ Socioeconomic status } \\
\hline Less than 5000 & 3 & 5.0 \\
\hline $5001-25000$ & 25 & 41.7 \\
\hline $25001-50000$ & 13 & 21.7 \\
\hline Above 50000 & 19 & 31.7 \\
\hline Total & 60 & 100.0 \\
\hline Less than 5000 & 3 & 5.0 \\
\hline \multicolumn{3}{|c|}{ Education } \\
\hline Illiterate & 6 & 10.0 \\
\hline Primary & 8 & 13.3 \\
\hline High & 10 & 16.7 \\
\hline Matric & 5 & 8.3 \\
\hline Intermediate & 9 & 15.0 \\
\hline Graduation & 15 & 25.0 \\
\hline Masters & 7 & 11.7 \\
\hline
\end{tabular}

Table-1: Demographic variables frequencies among Psychiatric patients

\begin{tabular}{|l|l|c|c|}
\hline \multicolumn{3}{|c|}{ Statistics } \\
\hline \multicolumn{2}{|c|}{} & Individual DMFT & CPITN \\
\hline \multirow{2}{*}{$\mathrm{N}$} & Valid & 60 & 60 \\
\cline { 2 - 4 } & Missing & 0 & 0 \\
\hline \multicolumn{2}{|c|}{ Mean } & 3.83 & 1.37 \\
\hline \multicolumn{2}{|c|}{ Std. Error of Mean } & 0.469 & 0.130 \\
\hline \multicolumn{2}{|l|}{ Std. Deviation } & 3.632 & 1.008 \\
\hline \multicolumn{2}{|l|}{ Minimum } & 0 & 0 \\
\hline \multicolumn{2}{|l|}{ Maximum } & 15 & 3 \\
\hline
\end{tabular}

Table-2: Statistical scores of DMFT and CPITN 


\begin{tabular}{|l|c|c|c|}
\hline \multicolumn{4}{|c|}{ Chi-Square Tests } \\
\hline & Value & df & Asymp. Sig. (2-sided) \\
\hline Pearson Chi-Square & $31.106^{\mathrm{a}}$ & 18 & 0.028 \\
\hline Likelihood Ratio & 36.720 & 18 & 0.006 \\
\hline $\begin{array}{l}\text { Linear-by-Linear } \\
\text { Association }\end{array}$ & 4.468 & 1 & 0.035 \\
\hline N of Valid Cases & 60 & & \\
\hline
\end{tabular}

Table-3: Chi Square Test for association between CPITN and Education

\begin{tabular}{|l|c|c|c|}
\hline \multicolumn{4}{|c|}{ Chi-Square Tests } \\
\hline & Value & df & Asymp. Sig. (2-sided) \\
\hline Pearson Chi-Square & $37.056^{\mathrm{a}}$ & 30 & 0.176 \\
\hline Likelihood Ratio & 40.183 & 30 & 0.101 \\
\hline $\begin{array}{l}\text { Linear-by-Linear } \\
\text { Association }\end{array}$ & 6.615 & 1 & 0.010 \\
\hline N of Valid Cases & 60 & & \\
\hline
\end{tabular}

Table-4: Chi Square Test for association between the CPITN and psychiatric disorder patients

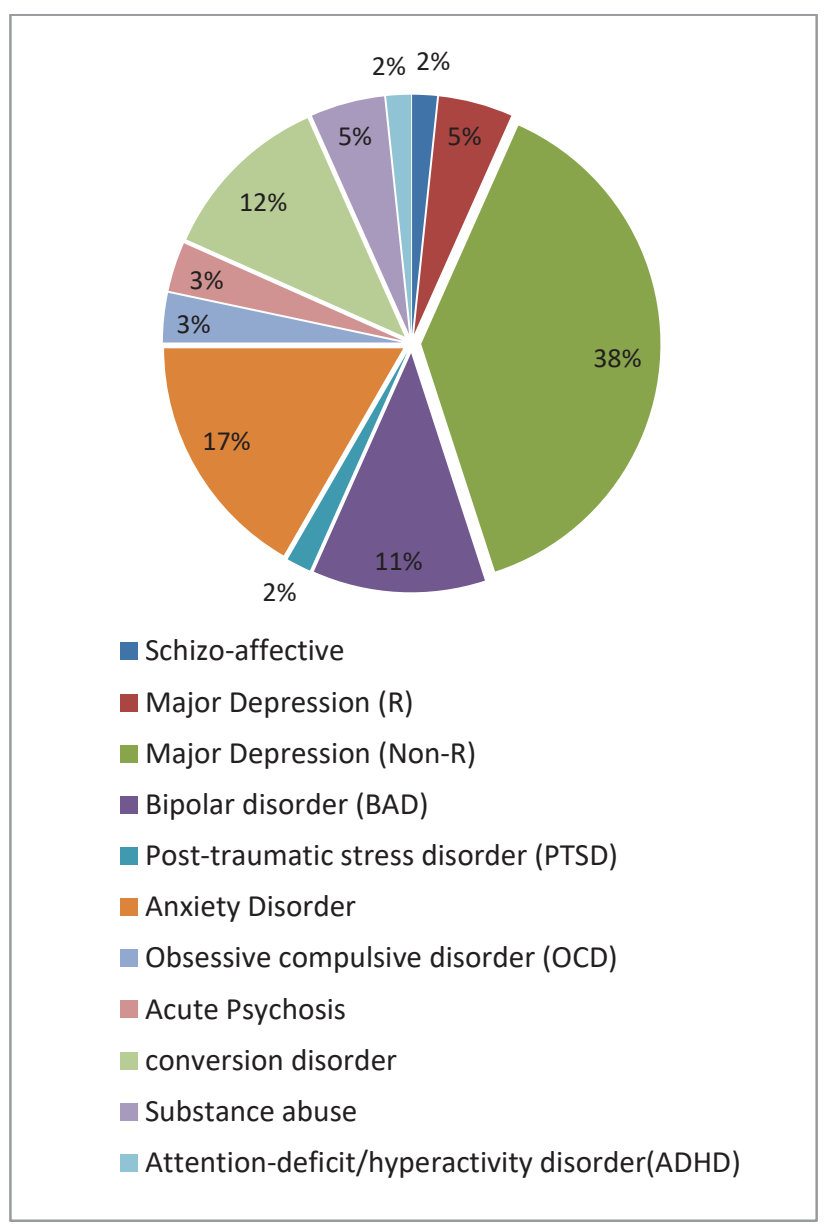

Chart-1: Different psychiatric diseases among the study group

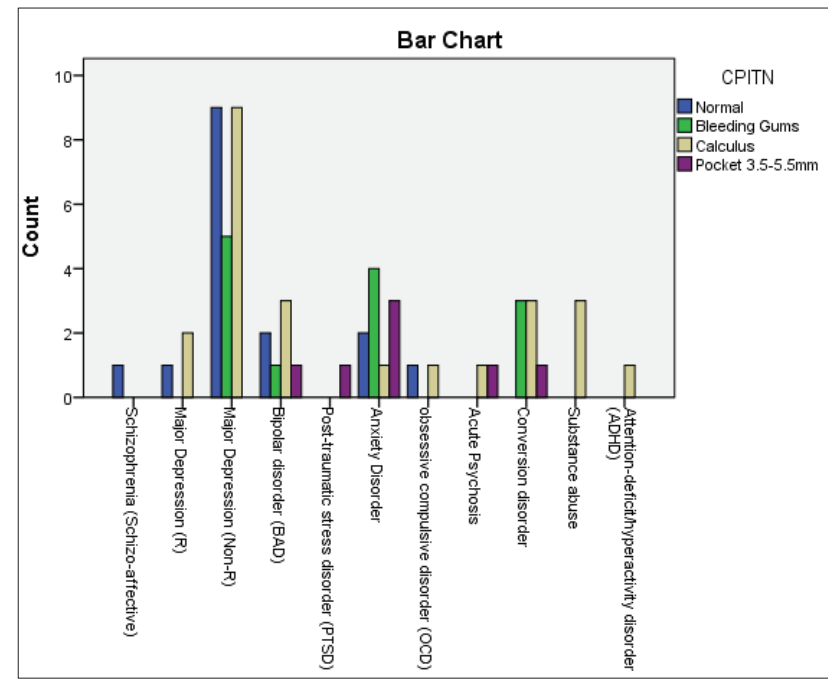

Chart-2: Psychiatric Diagnosis

\section{DISCUSSION}

A cross-sectional descriptive pilot study was carried out on the dental health of psychiatric patients presenting in Psychiatry O.P.D. of Sharif Medical Complex (SMC), Lahore over the duration of six months.

The most prevalent psychiatric disorder in the world is depression (300 million $)^{23}$ followed by bipolar disorder $(60 \text { million })^{24}$ and schizophrenia (23 million ${ }^{25}$ which are considered to be a main reason for suicide in $60 \%$ of these patients. ${ }^{26}$ Data on prevalence of psychiatric disorders in Pakistan is not available except one study mentioning $34 \%$ of Pakistani population suffering from depression and anxiety and another mentioning its prevalence in Punjab to be $44 \% .{ }^{27,28}$

In this study, patients were mostly seen to be more educated, with only $10 \%$ reported to be illiterate. The literate patients had more awareness of both psychiatric and dental health in comparison to illiterate patients. These patients obviously do not fully represent the features of the overall population but, literature reports that stress, anxiety and depression increased in literate people especially the college students. ${ }^{29,30}$ A study reviewing 14000 students from 26 different colleges in U.S. reported to have psychiatric problems in one third of the students, of which $36 \%$ spoke about the treatment they had taken during this time period. ${ }^{31}$ Another study quoted fifty percent of the college students getting treatment for depression and suicidal attempt. ${ }^{32}$ Seeking help for most of the students is a stigma and they tend not to take any help and this is one reason why there is an elevated risk for suicidal behavior. $^{33,34,35}$ 
Despite the population being from relatively urban area and with educated background, majority did not have healthy dental practice. Reflection of reduced oral health practice among psychiatric patients are evident from our findings of significantly increased frequency of caries among psychiatric patients also reported by Shah et al ${ }^{12}$ and Laloo et al. ${ }^{15}$

Literature reports large disparity regarding the frequency of caries and DMFT scores among the psychiatric patients. With regard to comparing our findings with studies in Pakistan, Maher et $\mathrm{al}^{36}$ in 1991 found the prevalence of caries to be very high in comparison to our current study. Whereas, Shah et $\mathrm{al}^{37}$ reports it to be 54.89 with mean DMFT $2.10+1.7$. Mirza et al reported it to be $65.5 \%$, Tang et al reported mean DMFT to be $9.5 \pm 8.9$ but highest was seen by Ramon et al who reported a mean DMFT score of 26.74 in comparison to our score which is $3.83 \pm 0.4690 . .^{38}$ Our score is also higher than 3 , which is the acceptable range of WHO.$^{39}$ On the other hand Shukla and Shrivastava reported it to be as low as $28 \%{ }^{40}$ Manish et al reported caries prevalence to be $32.2 \%$ with mean DMFT as low as $0.92 \pm 1.8 .^{41}$ Lower prevalence rate along with low DMFT values have been postulated to the presence of high concentrations of fluoride in their waters ${ }^{12}$ and can be a possibility in our group also as most of the patients coming to SMC are from Raiwind area which is reported to be having high levels of fluoride in the water. ${ }^{42}$

Our study found no association between various age groups and measure of dental health (DMFT) and no link between DMFT was seen with increasing age, however, Harchandani et al reports against our findings saying there is an increase in DMFT with increase in age. ${ }^{43}$ This can be attributed as a limitation of our study due to small sample size in our study.

In the current study, no association was seen between psychiatric medications and frequency of caries. It has been reported that a psychiatric medicine has a relationship with frequency of caries i.e., procyclidine (typical anti-psychiatric medicine) but in our study this medicine was not being used by the patients therefore abstinence from this medicine may be responsible for no relationship between the two groups. Similar findings has been reported by Biruktawit Kebede et al in his research. ${ }^{10}$

CPITN reveals periodontal health in our patients to be relatively better, compared to the condition of their teeth, with normal periodontium in $26.7 \%$ of the patients, however, this finding is seen to be in contrasts to Viral Shah et a ${ }^{37}$ reporting only $6.8 \%$ of the patients with healthy gingiva and Manish et al reporting healthy gingival to be only $1.9 \% .{ }^{41}$ Higher levels of calculus and pocket formation is been reported in literature i.e. 45.1 and $24.8 \%{ }^{12}, 71.8 \%$ and $72.9 \%,{ }^{44}$ respectively in comparison to $40 \%$ and $11.7 \%$ in our study population. However, Manish et al reported calculus to be in concordance with our study i.e. $40.6 \%{ }^{41}$ but not in pocket formation which is $35.3 \%$. A study by Diab et al reported pocket formation frequency to be $11 \%$ which is in cohesion to our study and calculus formation to be $31.3 \%$ which is closer to our study reporting $40 \% .{ }^{45}$ Differences in the calculations of calculus formation and pocket depths can also be postulated to multiple assessors involved and different skills involved in accurately using the CPITN probe.

Bleeding on probing has shown great variability in the literature and was seen to be high in our study sample i.e. $40 \%$ in comparison to many other studies reporting $16.5 \%,{ }^{37} 7.1 \%{ }^{44}$ and $10.5 \%{ }^{41}$ and this is as a result of poor oral hygiene practice of brushing once per day or no brushing at all as seen in $81 \%$ of our cases.

Among the different types of Psychiatric diseases, worst dental health was seen among the schizoaffective patients which is in contrast to data reported by Persson K et al. ${ }^{14}$ As this is a pilot study and number of patients is the limitation of the study. Studies with larger group could reveal more comparative analysis.

Overall this pilot study raises important questions regarding poor dental health of psychiatric patients especially patients suffering from schizophrenia as well as relationship of dental health findings with age, and oral hygiene practices. Low periodontal health index CPITN is seen to be significantly associated with education and soft tissues condition. In the current study the DMFT index proves high frequency of caries among the psychiatrist patients.

\section{LIMITATIONS}

This study needs to be followed up with a study with much larger sample size and compared with a control group. One of the limitations in our study was the large disparities among the different groups with depression disorder $43.3 \%$ and Schizophrenia, post-traumatic stress disorder (PTSD) and Attention deficit hyperactivity disorder (ADHD) with 1.7\%. Another limitation was smoking which has its own deteriorative effect on the oral health. Due to small sample size this factor was not ruled out from the study. Lastly the questionnaire was not fully standardized therefore results would be much better with fully standardized questionnaire. 


\section{CONCLUSION}

Frequency of caries, DMFT and CPITN scores are significantly greater in psychiatric patients with Major Depression (Resistant), substance abuse and post-traumatic stress disorder (PTSD). Decreased DMFT and CPITN scores are seen in schizophrenia, obsessive compulsive disorder (OCD) and bipolar disorder (BAD).

Recommendations: Psychiatric patient's family members or accompanied guardians constantly needs to emphasis on the patient to brush at least twice daily especially after meals and before going to bed, to prevent from any dental diseases or complications.

\section{REFERENCES}

1. Cullinan M, Ford P, Seymour G. Periodontal disease and systemic health: current status. Australian Dental Journal. 2009; 54:S62-S69.

2. Mirza I, Day R, Phelan M, Wulff-Cochrane V. Oral health of psychiatric in-patients: a point prevalence survey of an inner-city hospital. Psychiatric Bulletin. 2001; 25(4):143-45.

3. Scrine C, Durey A, Slack-Smith L. Enhancing oral health for better mental health: Exploring the views of mental health professionals. International journal of mental health nursing. 2018; 27(1):178-86.

4. Kisely S. No mental health without oral health. The Canadian Journal of Psychiatry. 2016; 61(5):277-82 .

5. Gupta S, Pratibha P, Gupta R. Necessity of oral health intervention in schizophrenic patients-A review. Nepal journal of epidemiology. 2016; 6(4):605.

6. Guo Y, Logan HL, Dodd VJ, Muller KE, Marks JG, Riley III JL. Health literacy: a pathway to better oral health. American journal of public health. 2014; 104(7):e85-e91.

7. Wei Y, McGrath PJ, Hayden J, Kutcher S. Mental health literacy measures evaluating knowledge, attitudes and help-seeking: a scoping review. BMC psychiatry. 2015; 15(1):291.

8. Yu Y, Liu Z-w, Hu M, Liu H-m, Yang JP, Zhou $\mathrm{L}$, et al. Mental health help-seeking intentions and preferences of rural Chinese adults. PloS one. $2015 ; 10$ (11): 0141889.

9. Jovanović S, Milovanović SD, Gajić I, Mandić J, Latas M, Janković L. Oral health status of psychiatric in-patients in Serbia and implications for their dental care. Croatian medical journal. 2010; 51(5):443-50.
10. Kebede B, Kemal T, Abera S. Oral health status of patients with mental disorders in southwest Ethiopia. PloS one. 2012; 7(6): e39142.

11. Spitzer RL, First MB. Classification of psychiatric disorders. JAMA. 2005; 294(15):1898-900.

12. Shah VR, Jain P, Patel N. Oral health of psychiatric patients: A cross-sectional comparision study. Dental research journal. 2012; 9(2):209.

13. Grewal H, Sharma H, Rajpal BM, Choudhary R. Oral health status of non-institutionalized psychiatric patients: a dentist perception. Del Psychiatric J. 2014; 17(1):44-47.

14. Persson K, Axtelius B, Söderfeldt B, Östman M. Monitoring oral health and dental attendance in an outpatient psychiatric population. Journal of Psychiatric and Mental Health Nursing. 2009; 16(3):263-71.

15. Lalloo R, Kisely S, Amarasinghe H, Perera R, Johnson N. Oral health of patients on psychotropic medications: a study of outpatients in Queensland. Australasian Psychiatry. 2013; 21(4):338-42.

16. Al-Mobeeriek A. Oral health status among psychiatric patients in Riyadh, Saudi Arabia. West Indian Medical Journal.2012;61(5):549-54

17. Kisely S, Quek L-H, Pais J, Lalloo R, Johnson NW, Lawrence D. Advanced dental disease in people with severe mental illness: systematic review and meta-analysis. The British Journal of Psychiatry. 2011; 199(3):187-93.

18. Cooper-Kazaz R, Levy DH, Sgan-Cohen HD. Severity of psychiatric disorders and dental health among psychiatric outpatients in Jerusalem, Israel. The Israel journal of psychiatry and related sciences. 2015;52(2):119.

19. Persson K, Axtelius B, Söderfeldt B, Östman M. Oral health-related quality of life and dental status in an outpatient psychiatric population: A multivariate approach. International Journal of Mental Health Nursing. 2010; 19(1):62-70.

20. Broadbent JM, Thomson WM. For debate: problems with the DMF index pertinent to dental caries data analysis. Community dentistry and oral epidemiology. 2005; 33(6):400-09.

21. Krueger RB, Reed GM, First MB, Marais A, Kismodi E, Briken P. Proposals for Paraphilic Disorders in the International Classification of Diseases and Related Health Problems, Eleventh Revision (ICD-11). Archives of Sexual Behavior. 2017; 46(5):1529-45.

22. Taylor MA, Amir N. Are schizophrenia and affective disorder related?: the problem of schizoaffective disorder and the discrimination 
of the psychoses by signs and symptoms. Comprehensive psychiatry. 1994; 35(6):420-9.

23. Della Crosse M, Mahan K, Hull TD. The Effect of Messaging Therapy for Depression and Anxiety on Employee Productivity. Journal of Technology in Behavioral Science.20181-5:1-5.

24. Hermens DF, Chitty KM, Kaur M. Mismatch negativity in bipolar disorder: A neurophysiological biomarker of intermediate effect? Schizophrenia research. 2018; 191:132-39.

25. Fleischhacker WW, Arango C, Arteel P, Barnes TR, Carpenter W, Duckworth K, et al. Schizophrenia - time to commit to policy change. Schizophrenia bulletin. 2014; 40 (Suppl_3):S165-S94.

26. Bani-Fatemi A, Polsinelli G, Kennedy JL, De Luca V. Ethnicity and suicide attempt: analysis in bipolar disorder and schizophrenia. BMC psychiatry. 2013; 13(1):252.

27. Husain N, Creed F, Tomenson B. Depression and social stress in Pakistan. Psychological medicine. 2000; 30(2):395-402.

28. Mirza I, Jenkins R. Risk factors, prevalence, and treatment of anxiety and depressive disorders in Pakistan: systematic review. Bmj. 2004; 328(7443):794.

29. Pedrelli P, Nyer M, Yeung A, Zulauf C, Wilens T. College students: mental health problems and treatment considerations. Academic Psychiatry. 2015; 39(5):503-11.

30. Wahed WYA, Hassan SK. Prevalence and associated factors of stress, anxiety and depression among medical Fayoum University students. Alexandria Journal of Medicine. 2017; 53(1):77-84.

31. Eisenberg D, Hunt J, Speer N, Zivin K. Mental health service utilization among college students in the United States. The Journal of nervous and mental disease. 2011; 199(5):301-08.

32. Downs MF, Eisenberg D. Help seeking and treatment use among suicidal college students. Journal of American College Health. 2012; 60(2):104-14.

33. Eisenberg D, Speer N, Hunt JB. Attitudes and beliefs about treatment among college students with untreated mental health problems. Psychiatric services. 2012; 63(7):711-13.

34. Golberstein E, Eisenberg D, Gollust SE. Perceived stigma and mental health care seeking. Psychiatric services.2008;59(4):392-99

35. Gianakis M, Carey TA. An interview study investigating experiences of psychological change without psychotherapy. Psychology and Psychotherapy: Theory, Research and Practice. 2011; 84(4):442-57.
36. Maher R. Dental disorders in Pakistan-a national pathfinder study. J Pak Med Assoc. 1991; 41(10):250-2.

37. Shah VR, Jain P, Patel N. Oral health of psychiatric patients: A cross-sectional comparision study. Dental Research Journal. 2012; 9(2):209-14.

38. Ramon T, Grinshpoon A, Zusman SP, Weizman A. Oral health and treatment needs of institutionalized chronic psychiatric patients in Israel. European psychiatry: the journal of the Association of European Psychiatrists. 2003; 18(3):101-5.

39. Bratthall D. Introducing the Significant Caries Index together with a proposal for a new global oral health goal for 12-year-olds. International dental journal. 2000; 50(6):378-84.

40. Shukla G, Srivastava R. A psychiatric study of cases attending dental OPD of a teaching general hospital. Indian journal of psychiatry. 1983; 25(3):198

41. Kumar M, Chandu GN, Shafiulla MD. Oral health status and treatment needs in institutionalized psychiatric patients: one year descriptive cross sectional study. Indian journal of dental research: official publication of Indian Society for Dental Research. 2006; 17(4):171-7.

42. Bashir MT, Bashir A, Rasheed M. Fluorides in the groundwater of Punjab. Pak J Med Health Sci. 2012; 6:132-35.

43. Harchandani N. Oral Health Challenges In Pakistan And Approaches To These Problems. Pakistan Oral \& Dental Journal. 2012; 32(3).

44. Tang WK, Sun FC, Ungvari GS, O'Donnell D. Oral health of psychiatric in-patients in Hong Kong. The International journal of social psychiatry. 2004; 50(2):186-91.

45. Diab HA, Hamadeh GN, Ayoub F. Evaluation of periodontal status and treatment needs of institutionalized intellectually disabled individuals in Lebanon. Journal of International Society of Preventive \& Community Dentistry. 2017; 7(3):76.

\section{The Authors:}

Dr. Saeed ur Rehman

Assistant Professor,

Department of Psychiatry,

Sharif Medical \& Dental College, Lahore.

Dr. Nauman Rauf Khan

Associate Professor,

Department of Oral Pathology,

Sharif College of Dentistry,

Sharif Medical \& Dental College, Lahore. 
Dr. Amna Nauman Khan

Associate Professor,

Department of Community Dentistry,

Sharif College of Dentistry,

Sharif Medical \& Dental College, Lahore.

Dr. Moeed Ramzan

Demonstrator,

Department of Community Dentistry,

Sharif College of Dentistry,

Sharif Medical \& Dental College, Lahore.

Dr. Eezzah Laraibe

House Officer,

Sharif College of Dentistry,

Sharif Medical \& Dental College, Lahore.
Dr. Hooria Haq

House Officer,

Sharif College of Dentistry,

Sharif Medical \& Dental College, Lahore.

Dr. Anum Abbass

House Officer,

Sharif College of Dentistry,

Sharif Medical \& Dental College, Lahore.

\section{Corresponding Author:}

Dr. Nauman Rauf Khan

Associate Professor,

Department of Oral Pathology,

Sharif College of Dentistry,

Sharif Medical \& Dental College, Lahore.

E-mail: dr.nrkhan@gmail.com 